The Journal of Public Space

2017 | Vol. 2 n. 4

\title{
VIEWPOINT
}

\section{In protest of apathy. The case of Panjim, Goa}

\author{
Namita Kambli \\ n.kambli@auckland.ac.nz
}

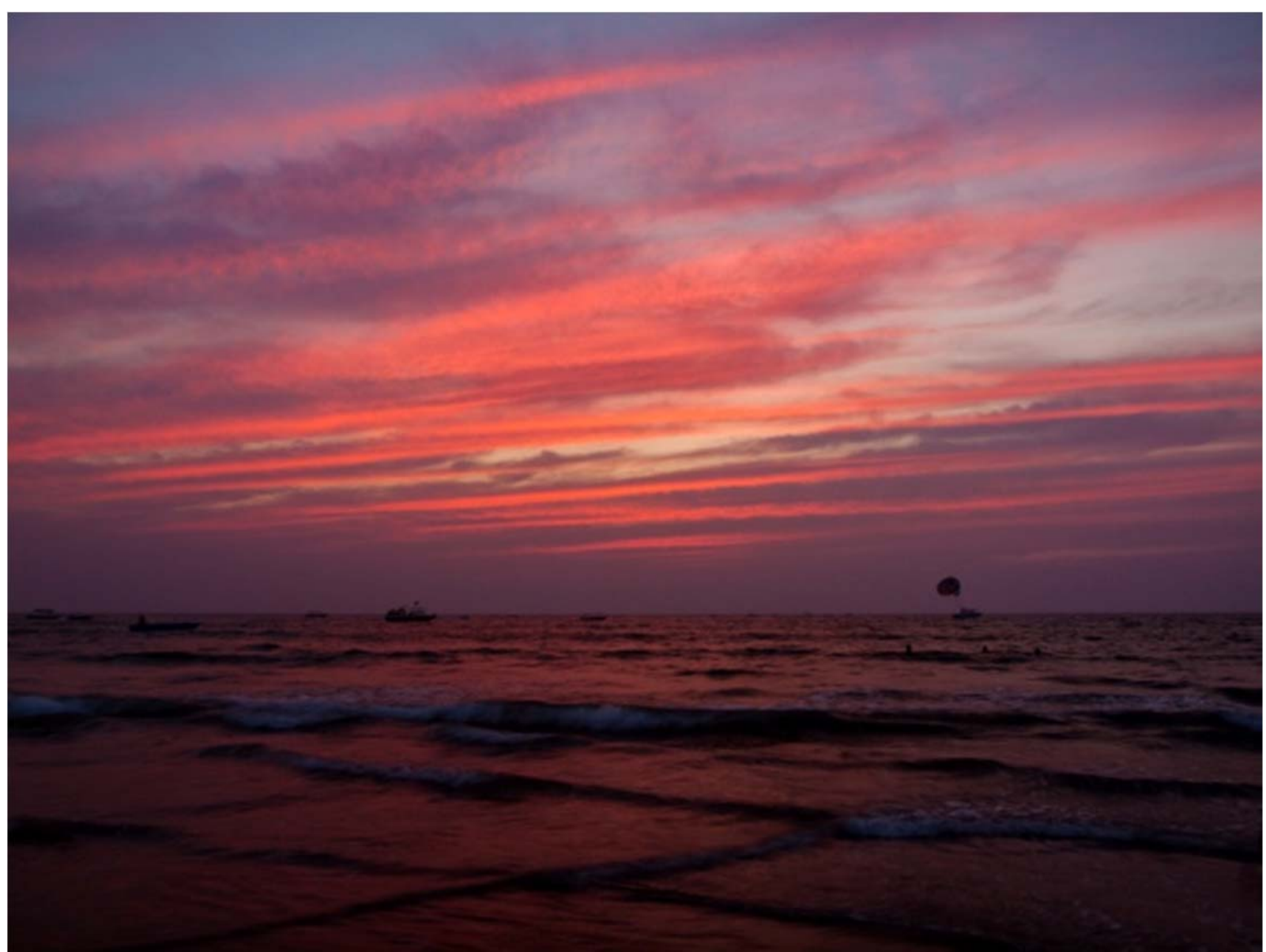

Sunset at Miramar beach. Source: Rakesh Ayilliath.

I never started out as a staunch defender of public spaces. My charming albeit small hometown - Panjim, Goa - did not have the quintessential town square, replete with small shops, fountains, and cafés. Instead, it was the local beach that served as a centre of social life, be it for gossiping, people-watching, or snacking on tender grilled corn-on-the cob. It was at this very beach where I first learnt to build wonky sandcastles with my red bucket and green spade. As a child, I did not give much thought to sharing my playground 
with tiny hermit crabs, elderly couples savouring soothing sunsets, and hippies with dreadlocks in search of nirvana.

To me, Miramar beach was a collective space, preordained to be enjoyed together. The above status quo remained the same as I went through school and high school, except that creative sand art took a backseat to giggling with other lanky teenagers at the beach face, with the occasional amused comment on exhilarated tourists seeing the ocean for the first time. Even then, I never fully appreciated the luxury of having a social sanctuary that was equally open to all. It was only as a fresh-faced architecture student that I came to better understand the role of Miramar as a public space. It was my internship in Pune, India, to be precise, that drove home the need for such places in the lives of ordinary citizens. A shortage of space in this bustling metropolis meant that malls served as gathering places, but of an entirely different nature. Like in other parts of the world, shopping centres were both expensive and exclusive, catering only to a select population. The social justice advocate in me was horrified at this development and profoundly grateful that Miramar still managed to stay true to the notion of public space a space in which people gathered to become "citizens of the world" (Norberg-Schulz, 1988: 55). This collective aspect of public space applied not only to Miramar, but to most of Goa's coastal stretch, its streets and parks, which were central to the state's culture and identity.

Specific to Panjim, locals and tourists seemed to respect and cherish its public spaces, which were clean and relatively well-kept for the most part. In addition to Miramar, the city boasted of two sports grounds, a majestic rain tree-lined boulevard leading up to a scenic riverfront, and a main market where fishmongers and vegetable vendors haggled with customers of all ages, all the while trading greetings and friendly jibes. These are amongst my fondest memories of Panjim. Nonetheless, as an expat who has now been away for more than a decade, my heart breaks a little for the city that awaits me each time I return, with streets choked by rule-flouting cars, off-shore casinos that are killing the capital's main river, and garbage becoming a perennial blot on the landscape.

As if it were not discourteous enough to double park on what were once pedestrianfriendly streets, it has also become fairly common for drivers to roll down their windows and casually throw trash onto the streets. The new market building, boasting endearing murals inspired by Goa's most famous cartoonist, is blighted by sprays of paan (betel leaf and areca nut) spit, thereby making the market appear unwelcoming and rundown. It is Miramar beach, however, that seems to be the worst affected. Mounds of plastic debris left behind by beachgoers have replaced sand dunes, and the shore is routinely awash with flip-flops, cigarette butts, and beer bottles, endangering both marine life and unsuspecting joggers. Worse still, a certain stretch of Miramar has been privatised by a luxury hotel and other stretches are often appropriated by groups of tourists, accordingly impinging on both the cleanliness and publicness of the beach itself.

Being a non-resident, or an 'outsider' as often labelled by other Goans, it is difficult for me to pinpoint the exact moment the tide began to shift or to decide who is responsible for it. Tourists are usually the first to be blamed, but given that they are not the sole users of Panjim's public spaces, it would be unfair to pin the blame entirely on them. The answer arguably lies in Carmona et al. (2008: 207) finding that cultural issues determine people's attitude towards public spaces i.e. how they act in them. In the case of India, a family-oriented culture has generally meant that the private domain is more valued than 
the collective, the latter being perceived as not belonging to anyone and hence no single individual's responsibility. This potentially explains why most Indian homes are spotlessly clean whereas the public realm is not. The same reasoning, however, does not entirely apply to Goa.
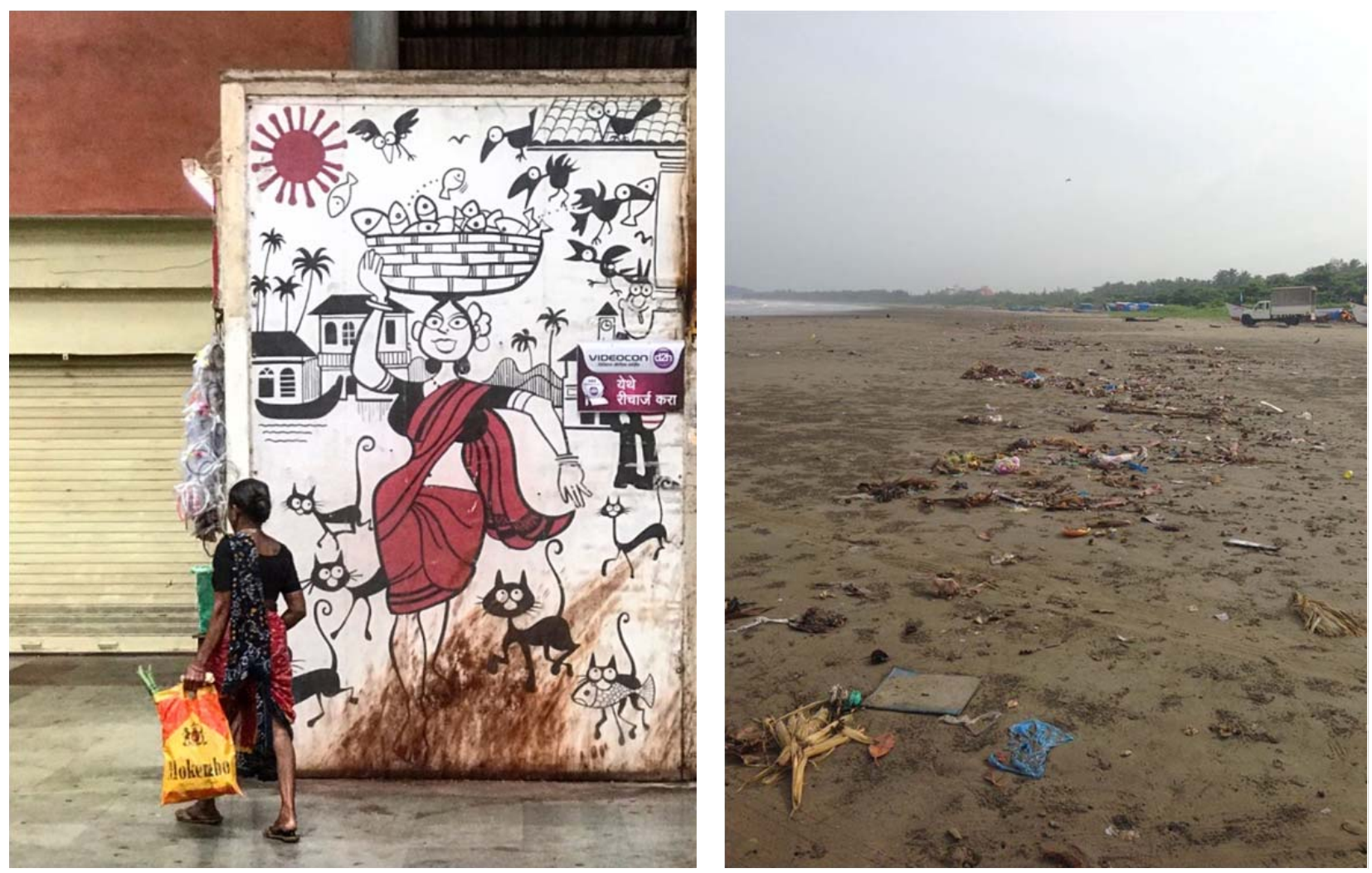

On the left: Mural at Panjim market covered in paan spit. Source: Manish P Pawar.

On the right: Garbage at Miramar beach. Source: Ajoy Barretto.

Having been a Portuguese colony until I96I, Goa is relatively different from the rest of India especially in terms of culture and form. The Panjim of my childhood is a clear testimony to the Indian-lberian fusion. This is what makes the increasingly blatant disregard for public spaces doubly distressing to me - both as an urbanist and as a Goan, regardless of my resident status. Impassioned discussions with friends and family members have led to one overwhelming conclusion: people either consider civic issues to be the government's responsibility or have resigned themselves to the woeful state of affairs. Therein lies the rub: APATHY. Prominent British anthropologist and UN messenger of Peace Jane Goodall (2002) calls apathy "the greatest danger to our future". In keeping with Goodall's assertion, it is my fervent belief that if we shrug off our individual responsibility to take care of our planet, cities, and public spaces, or if we let our feelings of helplessness overcome our desire to act, we will no longer have a planet to cherish or public spaces to gather in to revel in our shared humanity.

Reassuringly, Goodall puts forward hope as the antidote to apathy. In Panjim's - and Goa's - case, hope comes in the form of a citizen's initiative named Team Up to Clean Up GOA. This is a campaign that urges people to take responsibility for their surroundings 
and to desist from littering in order to protect the environment. The clean up drives organised by Team Up to Clean Up GOA have primarily focused on public spaces, including Miramar. It is true that similar clean up drives have been organised in the past by schools and organisations, such as the Rotary Club. Nonetheless, what makes Team Up to Clean Up GOA different is that it is a citizens' movement wholly initiated by civic-minded residents from all walks of life, united in their belief that they should be the change they want to see in Goa.

From the point of view of managing public space, what makes Team Up to Clean Up GOA's approach noteworthy is that it involves people directly in the process of making decisions related to public space. This is a key strategy of mitigating apathy towards public spaces (Carmona et al. 2008: 207). Enabling people to take ownership for their shared spaces fosters a stronger sense of civic pride and lays the foundation for a more considerate public space ethic. Given the utmost importance of public spaces in our lives, apathy simply cannot and must not be an option. What Panjim, and Goa, therefore need are more such movements in defence of public spaces. In short, Goa's future depends on it.

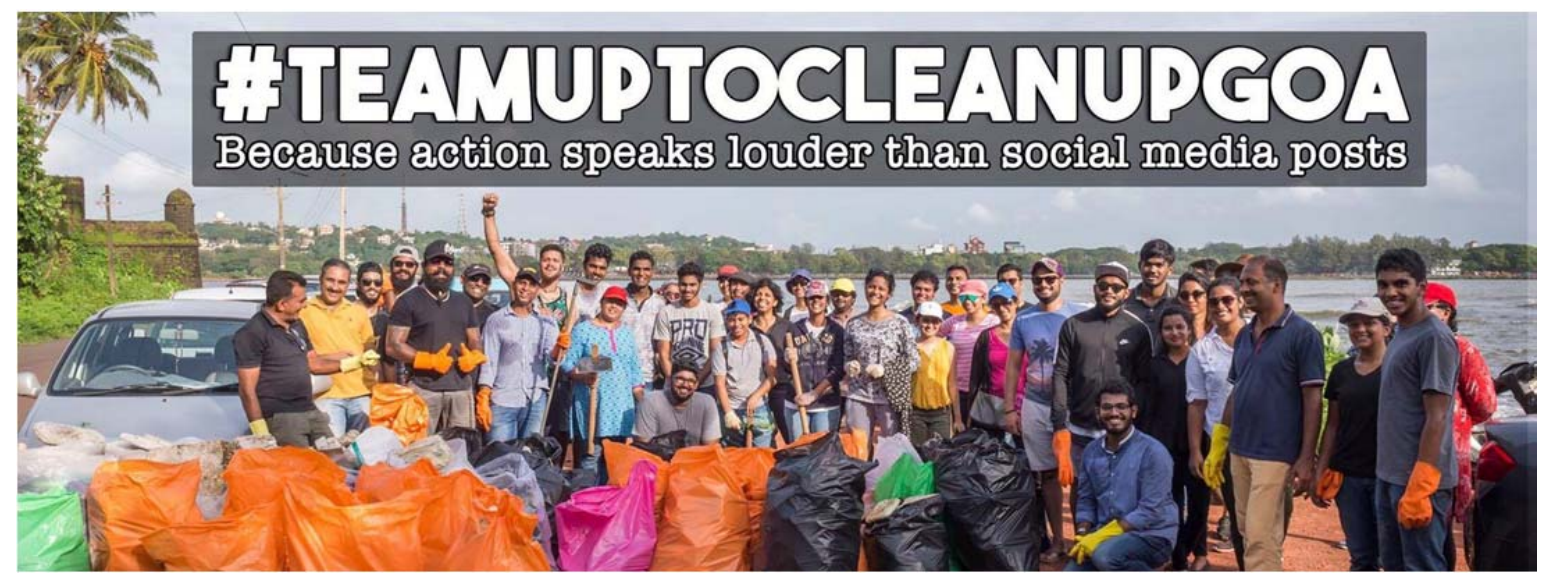

Post clean-up at Reis Magos Fort, Goa. Source: Team Up to Clean Up GOA.

\section{References}

Carmona, M., Magalhaes, C., Hammond, L. (2008). Public Space: The Management Dimension. New York and London: Routledge.

Goodall, J. (2002, Aug). The Power of One. Time. Retrieved from:

http://content.time.com/time/subscriber/article/0,33009, I003 I25-I,00.html

Norberg-Schulz, C. (1988). Architecture: Meaning and Place: Selected Essays. New York: Electa/Rizzoli.

\section{To cite this article:}

Kambli, N. (20I7). In protest of apathy: the case of Panjim, Goa. The Journal of Public Space, 2(4), I07-I I0. DOI: I0.5204/jps.v2i4.145

This article has been accepted for publication in The Journal of Public Space. Please see the Editorial Policies under the 'About' section of the journal website for further information.

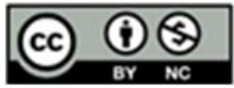

This work is licensed under a Creative Commons Attribution - Non Commercial 4.0 International License - https://creativecommons.org/licenses/by-nc/4.0/ 